\title{
Miniblocs and Fringe Currencies of the EMU
}

\author{
Patrick Honohan \\ World Bank and CEPR
}

\begin{abstract}
Like all major currencies, the Euro will attract a fringe of hangers-on. For EMU participants, the most important will be those with which participants already have significant trading and other economic relationships. These relation ships are not homogeneous across the EMU, but instead we can identify seven or more miniblocs, most of either are, or will be, split by the EMU. Stabilizing real exchange rate movements within these miniblocs could be of value in reducing the impact on EMU participants of asymmetric shocks. Possible institutional arrange ments to give effect to such a goal are considered. (JEL Classifications: F33, F36) ४Key Words : European M onetary Union, Currency unions>
\end{abstract}

\section{Introduction}

Each major currency has its fringe of hangers-on; the euro is no exception. Indeed by expanding the size of a currency area, one inevitably draws in a wider group of countries whose exchange rate policy focuses more and

\footnotetext{
* Correspondence Address: Patrick Honohan, 11 Cowper Gardens, Dublin 6, Ireland. (Tel) 353-1-491 1562, (Fax) 353-1-406 5422, (E-mail) phonohan@worldbank.org; M y thanks to Philip Lane and Charles Wyplosz for helpful comments. The findings, interpretations, and conclusions expressed in this paper are entirely those of the author. They do not necessarily represent the views of the World Bank, its Executive Directors, or the countries they represent.
}

(C2000 - Center for International Economics, Sejong Institution. All rights reserved. 
more on the core currency, in this case the euro. At the same time, the particular bilateral euro rates of most interest to individual EMU participants differs from participant to participant.

For this reason, the exchange rate policy of the EMU must be considered at two levels. The first (and most important) level has to do with overall or average foreign exchange value of the euro, and hence its value vis-á-vis the US dollar, the J apanese yen, and other major currencies. This paper is not concerned with the first level, but with the second, which relates to policy concerning specific bilateral exchange rates of the euro.

Regardless of what policy mechanisms are used at the first level, and with what effect, there remains scope for influencing specific bilateral exchange rates of the euro, and that is the focus of this paper. Although exchange rate policy in small countries almost never makes this distinction, accepting as exogenous the relative pattern of exchange rates between third currencies, policy in large countries will in general tend to affect cross-exchange rates. ${ }^{1}$ Accordingly, attention needs to be given to this dimension of policy. If crossrates are being affected by policy, against what criteria should these policy effects be measured? What instruments or institutional arrangements can and should be brought to bear on the matter?

Clearly, bilateral relations between the euro and some other currencies will be a matter of considerable focus both within and outside the EMU. The most obvious practical issue is the question of avoiding real misalignments and more generally smoothing bilateral euro exchange rates. Even abstracting from the transitional problem of the pre-ins, there are outsiders who will wish to peg their currencies to the euro. Already, before the euro came into operation, both the franc and the DM were used as pegs by non-members of the $E U$, and the ecu has been used in the past as the focus of with-margins adjustable pegs. And there are other countries in respect of which stability of bilateral real exchange rates may, for some or all members of the EMU, be particularly desirable.

Where EMU participants and the outsider in question have a common interest in stabilizing a particular bilateral exchange rate, there is a prima facie case for considering institutional arrangements to achieve such stabili-

1. Indeed, it is by definition small countries that cannot affect relative prices. 
ty. It does not, however, follow that the degree of concern about any given bilateral exchange rate is al ways the same on the part of outsiders and insiders. For example, an outsider may be able to shift part of the burden of a real supply shock onto EMU members by allowing an adjustment in the real exchange rate. Here too there could be potential scope for EM U exchange rate policy to shelter members from such effects. We will argue that a preset policy framework for dealing with these issues is likely to achieve a better outcome than ad hoc responses. ${ }^{2}$ Already an ERM $-I I$ arrangement has been announced for such members of the $E U$ as will not be participants in EMU. However, this arrangement is voluntary and extremely flexible, and represents a minimalist approach to the problem.

A variety of arrangements involving links between outsiders and the euro is likely. Some will continue to have an unilateral peg, such as the currency board arrangements of Estonia and Bulgaria (which are unilateral in that they do not require any action on the part of the Bundesbank or ECB). (And the credit facilities for a fixed peg enjoyed by the African franc zone countries have been transferred to their new euro peg). Other arrangements seem less attractive, such as external use of the euro as local currency, or a narrow-margins adjustable peg. A more promising route is the establishment of a negotiated target zone for minibloc partners, bolstered by credit arrangements. This would be likely to attract several adherents, offering potentially Pareto improvements.

Given that we are not here talking about policy for the overall average value of the euro, but rather for bilateral rates of particular concern, the next question to ask is what bilateral rates these might be. One important dimension derives from the problem of asymmetric real shocks affecting different EMU members. If bilateral exchange rate policy can be used to insulate or hedge these shocks, that will be a useful offset to the adverse side-effects of currency union membership. ${ }^{3}$

In fact, the trade patterns of different prospective EMU members are sub-

2. Essentially because an intertemporal trade can be effected whereby the ECB offers to help stabilize the bilateral exchange rate in the face of a nominal(demand for money shock) in return for the outsider's willingness to absorb real shocks.

3. It also offers a way of alleviating the problem, identified by von Hagen and Süppel[1994], whereby the differing objective functions of different members may not be optimally reconciled by a preset Central Bank constitution. 
stantially different, especially with respect to other members of the EEA and pre-accession countries with whom exchange rate arrangements could be realistically envisaged. Among this wider group of European countries one can identify at least seven clusters of closely-trading countries, most of which include both likely EMU participants and likely non-participants. A degree of real exchange rate stability within each cluster could help insulate the participant country from some real shocks hitting the cluster as a whole, but asymmetric with regard to the rest of the EMU. This is one basis for considering these clusters as potential mini-blocs. Other more subtle linkages are evidently present, as is evident for example in the correlated banking crises of the Nordic countries.

Even if a welfare-improving mini-bloc exchange rate policy cannot be arrived at, financial market derivatives of the relevant exchange rates could possibly be employed as part of a hedging mechanism for the EMU members concerned. While that would seem to be a matter for national fiscal authorities (as being an aspect of national debt or treasury management policy), issues of monetary diplomacy arise (cf. Kirshner [1995]), which would need to be considered at the level of the EMU as a whole.

The remainder of the paper is organized as follows. In order to motivate the problem with a conspicuous and concrete example, we begin in Section II with an account of the interdependence of Ireland and the UK, which represent what is probably the most conspicuous minibloc. Though the exchange rate of sterling with the euro will be a very sensitive issue for Ireland, it is unlikely that a cooperative solution will be found here. Section III outlines how the problem of asymmetric shocks can be magnified for minibloc members by exchange rate movements; the potential for welfare gains from exchange rate cooperation, or from use of exchange rate-related financial derivatives to hedge risks to participants is discussed. (The reasoning is spelled-out in a simple model presented in the Appendix). Based on analysis of trade patterns, Section IV identifies and discusses seven potential miniblocs on the fringe of EMU. They are the Insular, the Nordic, the Iberian, the Central European, and the Baltic, together with two centered around Italy and Greece. Four of these have been formally split by the euro; two others are either split de facto, or soon will be. Section $V$ concludes with a brief discussion of the some of the practical issues of cooperative arrange- 
ments between the EMU and outsider minibloc partners.

\section{The Insular Minibloc}

The most conspicuous potential minibloc split by EMU is that formed by Ireland and the UK. The preoccupation of Irish policymakers and commentators with the Irish pound/ sterling exchange rate also represents what is probably the most important instance of a particular concern with bilateral rates. Although Irish-UK economic linkages have sharply weakened over the past three decades, they remain strong in terms of trade, financial linkages, migration, and possibly price and wage setting behavior.

Twenty-five years ago, on the eve of EEC membership, the UK bought $62 \%$ of I rish exports (at that time still predominantly agricultural produce) and provided as much as $55 \%$ of imports. Since then the growth of Irish manufacturing, spearheaded by inward foreign direct investment by US and other multinationals (which account for almost a half of manufacturing employment, and a much higher share of measured output), ${ }^{4}$ has been associated with a rapid expansion and geographical diversification of exports. EU membership has also contributed to this diversification. Nevertheless, the UK still accounts for a quarter of I rish exports and rather more $35 \%$ of imports.

Although they too have diversified away from the UK, I rish-owned firms sell disproportionately to the UK (B aker et al. [1996]), and the labor intensity of exports to the UK is also higher than average, so that the importance of UK trade to Irish nationals is higher than suggested by the export shares.

4. An important reason for inward FDI to Ireland is the favorable corporate tax regime. Accordingly it is not surprising to find that the average measured profit share in output of foreign-owned firms is exceptionally high, even when analyzed on a sectoral basis. This partly reflects the operation of transfer pricing (capital formation by these firms is not especially high) and as a result output and export data need to be interpreted with care. Similar issues arise with the operation of offshore financial institutions in the tax-favoured Dublin International Financial Services Centre. The potential magnitude of these effect may be judged by the size of profits earned in Ireland by foreign-owned firms. This amounted to almost US $\$ 9$ billion in 1995 ( $14 \%$ of GDP) 
In terms of invisibles, the UK represents an important source of tourists to I reland, even if it has not retained its share in the face of the boom in I rish tourism that has occurred over the past decade.

Sharp movements in the Irish pound/ sterling exchange rate have a considerable effect on the performance of Irish exports and tourism. The role of the 1986 devaluation of the Irish pound in contributing to the late 1980s recovery has been well documented.

For trade in the opposite direction, the UK still accounts for over onethird of I rish imports, disproportionately consumer goods. This has made Ireland the UK's fourth largest customer in some recent years; though at about $5 \%$ I reland's share in UK exports is of relatively minor importance. ${ }^{5}$

Financial linkages are also very close. Until shortly before EM S membership in 1979 the Irish financial system was essentially an annex of the sterling market based in London. The credibility of the one-for-one sterling link, and the extensive use sterling by financial institutions, companies and individuals, kept Irish interest rates close to those in London (Honohan [1997a]). Indeed, it was only after the sterling link was broken in 1979 that I reland began to display a systematic pattern of excess returns, averaging more than $2 \frac{1}{2} \%$ per annum against Germany. In addition, after 1979 , the combination of continued close institutional links and regressive expectations with regard to the Irish pound/ sterling exchange rate had the effect of destabilizing interest rates, which - until the final glide to EM U entry - rose whenever there was a sharp rise in the sterling value of the Irish pound (Figure 1). While the regressive element in exchange rate expectations has been fulfilled on average (at end 1998 the rate was 0.89; the average for $1996,1.03)$ it is interesting to note that the market systematically exaggerated the degree to which sterling weakness predicted a fall in the Irish pound/DM exchange rate (Honohan and Conroy [1994]). This serves to highlight the fact that perception as well as reality is involved in creating these Irish/ UK financial linkages.

There is substantial integration of the labor market too across the Irish Sea. The UK is still the major destination of Irish migrants, and econometric analy-

5. N orthern Ireland represents only about one-tenth of this trade of the UK with (the Republic of)Ireland. 
Figure 1

Irish Sterling Exchange Rate and Irish£ -DM Interest Differential

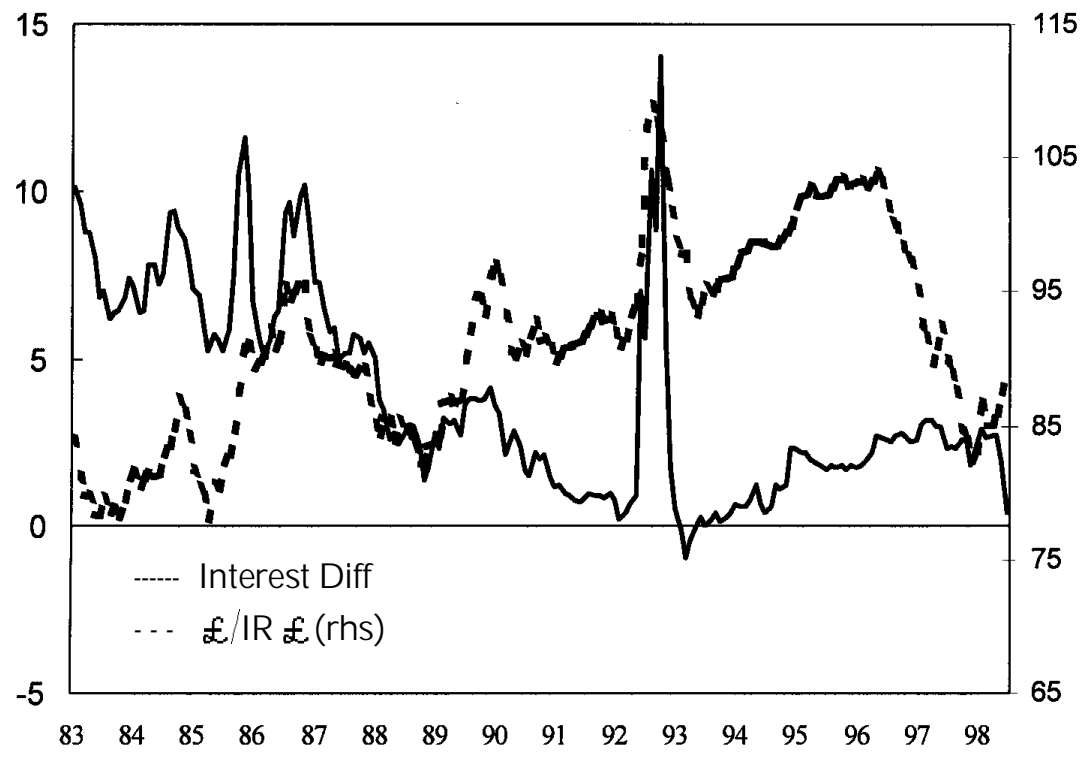

sis shows that migration flows are strongly influenced by relative labor market conditions. Indeed, there has been a medium-term tendency for the Irish unemployment rate to adjust to movements in that in the UK, though this is superimposed on some longer-term trends (Honohan [1992]).

Finally, one may mention the fact that UK wages and prices appear to have been more important than other foreign prices in driving short-term movements in wages and prices in Ireland (Curtis and Fitz Gerald [1994], Kremers [1990]). This is variously attributed to institutional links (at the level of wholesale distribution and trade unions, for example) or to the nature of exchange rate expectations.

The overall effect of these linkages is to elevate the importance of the bilateral Irish pound/sterling exchange rate both in reality and in policy debate. Ireland's three large devaluations in the EMS all followed strong surges in the Irish pound against sterling, and conversely every strong surge in the rate was followed by a devaluation. In January 1993, it was an easing of UK monetary policy and a further slippage in sterling that ended 
the Irish authorities' four-month attempt to preserve the EMS peg in the face of the withdrawal of sterling. That attempt had seen episodes of threedigit money market interest rates - despite strong economic growth and a large surplus on the current account of the balance of payments.

Given this experience, there is well-founded concern as to what the consequences for Ireland in the EM U will be when a non-participating sterling fluctuates sharply. If sterling has a tendency to fall, how badly will Irish exporters and those involved in the tourist trade be hit? Can Irish wages and prices adjust sufficiently quickly? If not, will the employment and output consequences display hysteresis? If nominal interest rates are common across the EMU, will this imply higher real interest rates for Ireland, considering the systematic decline in attainable export prices? While the magnitude of these effects need not be so great as to wipe out other benefits of EM U membership, ${ }^{6}$ it is clear that Ireland would prefer sterling to be stable against the euro, at least provided that such stability did not weaken UK economic performance and import demand. It is not so obvious that sterling stability against the euro would be good for the UK also, and that (of course) is what creates the Irish-UK minibloc "problem".

\section{Transmission of Shocks from Outsiders to Participants and the Potential for Welfare Gains}

There are many circumstances under which the exchange rate policy of outsiders could become a matter of concern to insiders. On the other hand, outsiders may also wish to insulate themselves from unwanted movements in their exchange rate vis-à-vis the euro. There is no contradiction here: depending on circumstances the outsider may wish their currency to depreciate, or to remain stable. A pre-arranged policy can help insulate the outsider from unwanted shocks at the cost of its forgoing the opportunity for competitive devaluation.

For example, suppose that two countries, one a member of EMU, the

6. While Irish economists have been split on this issue, a substantial middle ground is exemplified by the recent model-based estimate (Baker et al. [1996]) suggesting that the measurable economic effects net out just on the positive side of zero. 
other an outsider, are linked by trade and are both vulnerable to a common source of shocks that do not affect the rest of the EMU. An adverse shock hitting this two-country minibloc may be absorbed by a depreciation of the outsider's cur rency against the euro. But the insider does not benefit from currency depreciation. Rather the contrary: its trade-weighted exchange rate will appreciate, worsening the shock. The insider would prefer the outsider's cur rency not to depreciate.

$\mathrm{N}$ ote that the fact that there is such a minibloc, containing an EM U-outsider, worsens the familiar problem of asymmetric shocks. Even if there were no outsider, an insider hit by a specific shock could still be hurt by the inability to use the exchange rate to cushion the shock. But the outsider's currency is depreciating in response to the common shock, and thereby induces a higher effective or trade-weighted appreciation in the insider's exchange rate than in the EMU's average trade-weighted exchange rate.

The minibloc factor thus amplifies the cost of asymmetric shocks on EMU members who are part of a minibloc. The problem may be restricted to sectors or regions of an insider that are particularly closely related to the outsiders, but that does not remove the problem.

Is there a policy solution which can reduce this problem? Clearly, fixing the euro exchange rate of the outsider would do the trick. But, as presented so far, this would not be in the outsider's interest, since it would be deactivating a useful insulating mechanism. Other factors might induce the outsider to favor a cooperative exchange rate relationship. For example, the exchange rate of a small outsider might be subject to unwelcome speculative pressure that could be seen-off by intervention policy backed by the $E C B$. The outsider might be prepared to forgo the shock-insulation of the real economy provided by a floating exchange rate if it could rely on help in insulating the nominal exchange rate from destabilizing speculation.

The Appendix shows how this kind of trade-off can make sense in terms of a formal model where the outsider's exchange rate is market-clearing, but where trade and speculative motives both influence the market-clearing rate. It also points out how the insider could buy insurance against the shock by purchasing financial market derivatives tied to the value of the outsider's cur rency. As the acquisition of the insulating portfolio would involve downward pressure on the outsider's currency, it would be of interest only 
to a small insider with a big outsider.

The model of the Appendix and our discussion picture the linkage between insider and outsider as happening through trade linkages and real shocks. But any of a variety of shocks could transmit themselves into analogous situations.

\section{Mapping Interdependency: the Mini-blocs Identified}

\section{A. Using Trade Patterns to I dentify Miniblocs}

The discussion of Section III (and the model of the Appendix) emphasizes international demand spillovers as the channel through which interdependency of different countries takes effect. In the same spirit, though there are clearly several other types of channel which are empirically important, including the correlation of exogenous shocks, this section focuses mainly on trade patterns in constructing an indicative geography of interdependence. ${ }^{7}$ We look at historical data, though it must be borne in mind that trade patterns will continue to evolve in response to the integration of the transition economies into the world economy, to the lowering of trade barriers to the pre-accession countries, and possibly to the EMU itself. ${ }^{8}$

Therefore we turn to the country composition of trade between some thirty countries selected as having been or currently being considered as mem-

7. For the present purpose, indeed, analysis of the correlation between the shocks affecting different currencies is arguably even more relevant that for the Optimal Currency Area literature, in that high and significant correlations are potentially constructive of miniblocs, whereas low correlations only cast doubt on pre-hypothesized OCAs (cf. Bayoumi and Eichengreen [1996], Demertzis, Hughes Hallett and Rummel [1996]). On the other hand heavy reliance on historical output shock covariances to construct blocs is likely to run into the problem of instability of correlations familiar from attempts to construct minimum-variance portfolios from historical asset return correlations. Anyway, from a practical point of view, we lack (for many of the countries of interest) the long time series of output that would be required to implement a Blanchard-Quah type decomposition. For what it is worth, the raw output growth correlations do not yield similar clustering to the trade patterns discussed in the text. B eyond trade and production patterns, the nature of interdependence in the miniblocs varies widely, including financial linkages(cf. Honohan [1997b]). 


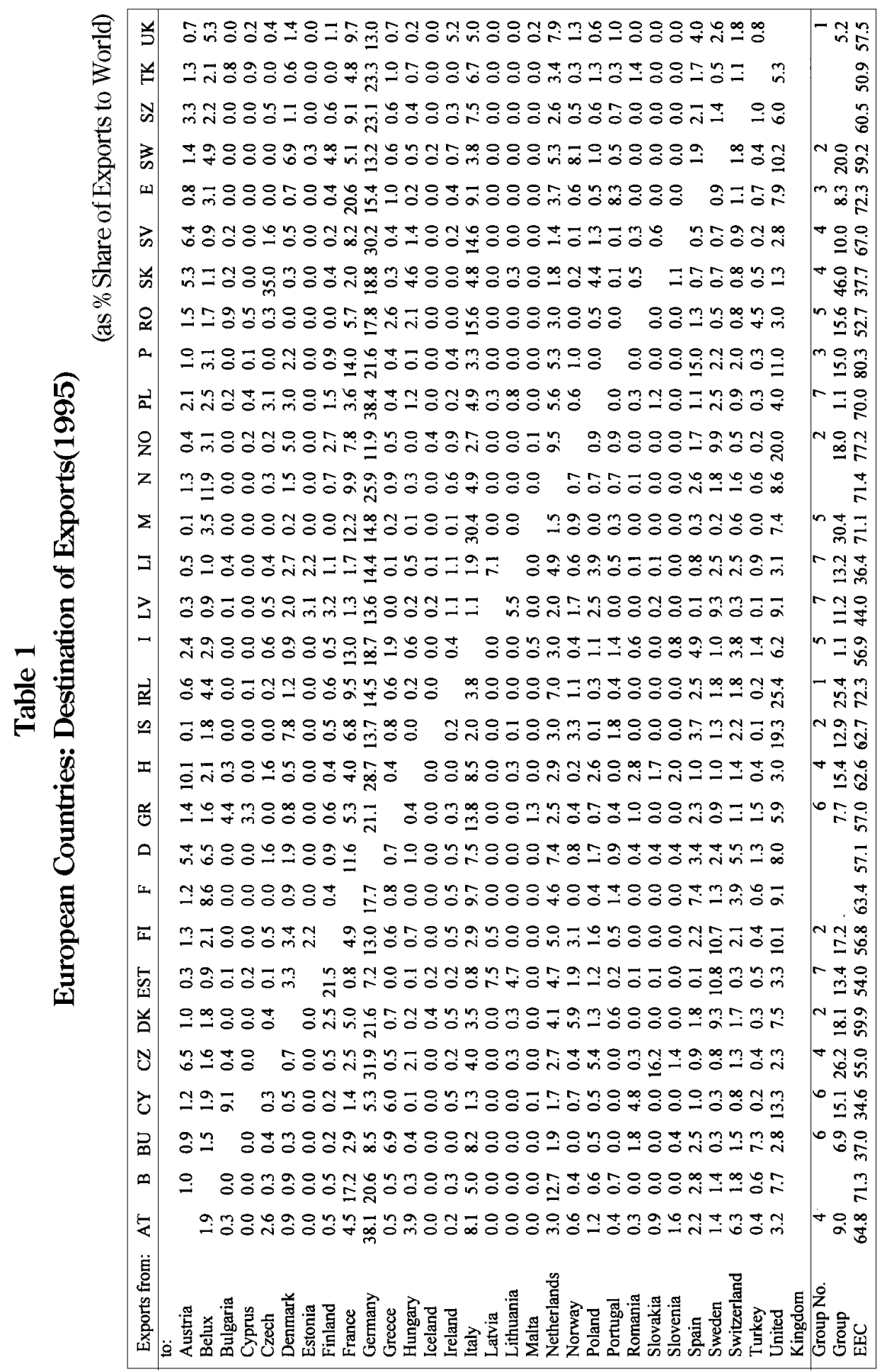


bers of the EU or EEA. The list thus includes all fifteen current members of the EU (though Belgium and Luxembourg are treated as a unit); twelve "preaccession" countries in Eastern Europe ${ }^{9}$ and the Mediterranean ${ }^{10}$; and two EEA countries, Iceland and N or way. ${ }^{11}$

Each column of Table 1 shows the distribution of one of these countries' exports to the remainder of the group. ${ }^{12}$ The same data is rearranged in Table 2 to show the difference in \%points between each element in Table 1 and the corresponding row weighted average. For example the 4.8 under Czech republic in the row for Austria indicates that the Czech Republic's exports to Austria, at $7.3 \%$ of total Czech exports, was $4.8 \%$ points above the (weighted) average share which Austria took of all of these countries' exports.

A variety of alternative statistical clustering techniques can be employed to assist in the identification of miniblocs. For example, if the excess trade share elements of Table 2 are denoted $a_{i j}$, then writing $c_{i j}=a_{i j}+a_{j i}$ we obtain a symmetric similarity matrix to which we can apply the nearest-neighbour method of clustering to arrive at the tree shown in Figure 3 (which is based on omitting the core EU countries of Germany, France and Benelux)..$^{13}$ The clustering, though it eventually links all the countries shown, clearly sug-

8. The role of preferential trade arrangements in influencing trade patterns away from what would be predicted by a gravity model is described and quantified in Bayoumi and Eichengreen [1995]. The general issue of the endogeneity of factors influencing the optimality of regional arrangements is discussed by Frankel and Rose [1996].

9. Bulgaria, Czech Republic, Estonia, Hungary, Latvia, Lithuania, Poland, Romania, Slovakia, Slovenia.

10. Cyprus and M alta. Some data is also provided for Turkey.

11. Some data is also provided for Switzerland.

12. The data is drawn from the United Nations Yearbook of International Trade Statistics [1994-1995]. Trade patterns are no doubt endogenous to the exchange rate regime (and will evolve under other pressures too, especially in the transition economies). Nevertheless most of the qualitative interdependencies documented here are likely to remain relevant for the foreseeable future.

13. This method builds clusters by starting with biggest element in the similarity matrix, say $c_{i j}$, and forming the first cluster with $i$ and $j$ as founder members. The process continues with the next highest value. When one arrives at $c_{i j}{ }^{\prime}$, then if $i$ ' is already $a$ member of a cluster, then j' also joins that cluster along withe the members, if any, of its own cluster. 





gests (as indicated on the Figure) seven mini-blocs on the geographical periphery of Europe showing relatively intensive within-group trade. N ote that this excess-trade-share metric of Table 2 highlights unusual dependency rather than dependency per se. Thus for example, while the UK is one of Finland's largest customers, taking $10 \%$ of Finland's exports, this share is only $2 \%$ points higher than the UK's weighted average share of all the exports shown: as such, the Finland-UK link does not show as exceptional in the Table.

Alternatively, one can use the full vector of trade shares from Table 1 and employ clustering techniques on the similarity of these vectors. Figure 4 shows one such clustering. ${ }^{14}$ Once again the same miniblocs are evident, showing that the proposed miniblocs share an overall pattern of within-EU trade, as well as having relatively intensive within-group trade.

A very simple way of grouping the countries is shown in Figure 2 which draws ar rows between country pairs where exports exceed the average by $3 \%$ points or more..$^{15} \mathrm{Here}$ the arrow goes from the exporter, thus allowing one to see which is the dependent country in the pair. It is immediately evident from Figure 2 that these linkages are easily interpretable in terms of geographical nearness. Once again, if we ignoring the core group of Germany, Benelux and France, the arrows diagram also conveys the seven mini-blocs.

Table 3 lists these trade mini-blocs together with the share of each country's exports that goes to its minibloc partners and the share that goes to the EU-15. The miniblocs are quite diverse in their character, some contain some countries which (in terms of the Figure 2 linkages) are exporting-only members, in the sense that they do not import disproportionately from the other members, while others are importing-only members. The motivation for limiting exchange rate movements will be quite different as between

14. In contrast to the nearest-neighbour algorithm described for the similarity matrix in the previous footnote, this uses an average-pair method of clustering (with Ward's covariance adjustment).

15. Out approach differs from the used by Ben-D avid[1995] to form trade groups which might explain faster income convergence. He begins with source countries and forms groups around each these by including all countries representing more than 4 per cent of the source country's exports. His approach yields overlapping groups. 
Table 3

Trade of Miniblocs

\begin{tabular}{|l|c|r|r|r|c|}
\hline & Group & \multicolumn{2}{|c|}{ \%Share of exports going to } & \multicolumn{2}{c|}{ \%Share of imports coming from } \\
\cline { 3 - 6 } & No. & Group & EMU-12 & Group & EMU-12 \\
\hline Ireland & 1 & 25.4 & 43.6 & 35.5 & 19.7 \\
United Kingdom & 1 & 5.2 & 53.5 & 4.1 & 52.8 \\
\hline Denmark & 2 & 18.1 & 47.3 & 20.4 & 53.8 \\
Finland & 2 & 17.2 & 34.2 & 18.2 & 36.2 \\
Iceland & 2 & 12.9 & 36.6 & 2.7 & 4.1 \\
Norway & 2 & 18.0 & 41.3 & 27.1 & 36.6 \\
Sweden & 2 & 20.0 & 48.2 & 19.0 & 50.9 \\
\hline Portugal & 3 & 15.0 & 64.6 & 20.7 & 65.6 \\
Spain & 3 & 8.3 & 61.6 & 2.9 & 54.8 \\
\hline Austria & 4 & 9.0 & 59.5 & 5.1 & 62.9 \\
Czech & 4 & 26.2 & 44.6 & 8.4 & 44.7 \\
Hungary & 4 & 15.4 & 47.8 & 16.0 & 44.6 \\
Slovakia & 4 & 46.0 & 29.9 & 35.3 & 26.2 \\
Slovenia & 4 & 10.0 & 56.4 & 15.7 & 55.6 \\
\hline Italy & 5 & 1.1 & 45.1 & 1.0 & 50.5 \\
M alta & 5 & 30.4 & 64.1 & 26.8 & 56.6 \\
Romania & 5 & 15.6 & 45.1 & 13.2 & 40.8 \\
\hline Bulgaria & 6 & 6.9 & 25.7 & 4.5 & 25.8 \\
Cyprus & 6 & 15.1 & 13.9 & 7.3 & 28.9 \\
Greece & 6 & 7.7 & 48.3 & 1.7 & 57.6 \\
\hline Latvia & 7 & 11.2 & 25.0 & 12.2 & 33.9 \\
Lithuania & 7 & 13.2 & 28.1 & 9.1 & 27.9 \\
Poland & 7 & 1.1 & 58.5 & 0.2 & 52.6 \\
Estonia & 7 & 13.4 & 38.2 & & \\
\hline Belgium/ Lux & & & 60.2 & & 66.6 \\
France & & & 50.2 & & 53.9 \\
Germany & & & 39.5 & & 42.1 \\
Netherlands & & & 58.0 & & 49.5 \\
\hline Switzerland & & & 48.6 & & 67.1 \\
Turkey & & & 42.5 & & 38.7 \\
\hline
\end{tabular}


these two; the former being more dependent on the latter. These asymmetric members are mentioned below; except where so mentioned all countries are both exporting and importing members of the relevant minibloc.

The four miniblocs split by the EM U are:

Insular: This minibloc is formed of two EU (Ireland and the UK) members, one of which has opted out of early EMU participation. The UK is an important export destination for other countries too (Cyprus, Iceland, Norway), but only I reland bulks significantly in UK exports as well. N evertheless, Ireland is clearly the dependent partner in this minibloc. Because of the asymmetry of this minibloc, and the size of the UK economy, it would be unrealistic to assume that Ireland's vulnerability to UK exchange rate shocks would be influential in determining UK exchange rate policy with regard to the euro.

Nordic : This minibloc, including all the Nordic countries (Denmark, Iceland, N orway, Sweden and Finland), accounts for between 17 and $20 \%$ of its participants' exports, except for Iceland (an exporting-only member), which exports about $12 \%$ within the minibloc. All of these countries have at least $55 \%$ of their exports within the EU. (These countries also have strong trading links with the UK, and the within-minibloc share of the $\mathrm{N}$ ordic countries would rise to a minimum of $26 \%$ if the UK were included).

Central European : This group (most of whose members also trade disproportionately with Germany) includes the important Czech-Slovak subgroup, together with Austria and Slovenia (which also exports strongly to Italy, included in a different minibloc). With their unit labor costs likely to remain much lower for many years to come, and their current and prospective emphasis on price-sensitive export products, the Czech Republic and Slovakia may, as they climb the quality scale, become increasingly important competitors for Austria and parts of Germany, giving rise to concern about any competitive devaluation. On the other hand, their proven vulnerability to currency speculation could make them interested in cooperative arrangements with the euro area that could help them resist such pressure.

Mediterranean : The Italian minibloc includes $M$ alta and Romania, which are dependent exporting-only partners. Italy is an importing-only member, but for M alta in particular - a third of whose exports go to Italy - 


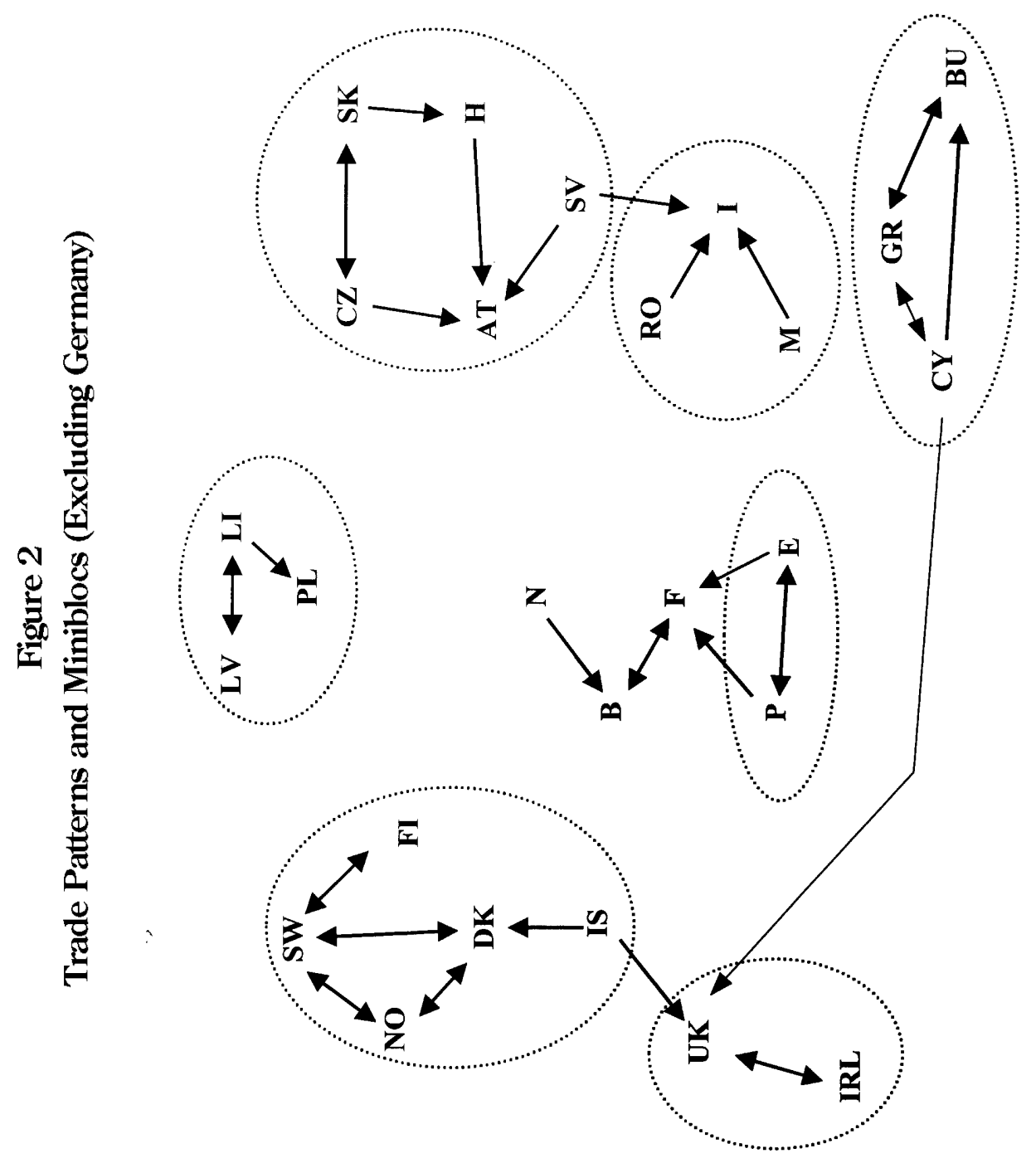


Figure 3

Cluster B ased on Bilateral Trade Shares

(Similarity M atrix: Closest Pair M ethod)

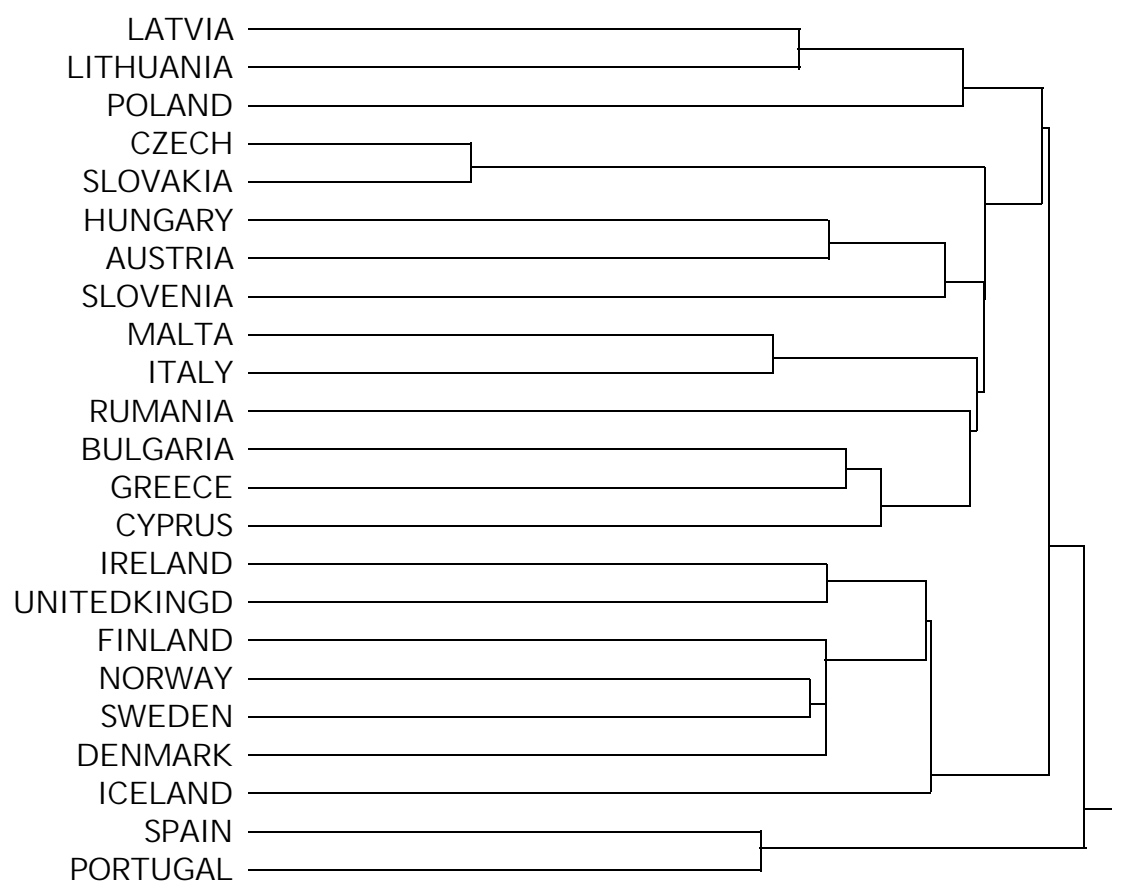

the exchange rate issue will be an important one. Malta's position is also strongly influenced by the tourist trade, within which there is a different pattern of interdependency, as Cyprus and $M$ alta compete with each other, and with Greece, Spain, Portugal and I taly (along with other countries not included in our set) as Mediterranean sun holiday destinations. As such, one begins to recognize a common interest in the sun resorts of the latter countries to ensure that none of the island destinations indulge in competitive depreciation.

Although historical experience does not support the idea of a fixed or systematic relationship between the currencies of our miniblocs, and although trade patterns are no doubt endogenous to the exchange rate regime (and will evolve under other pressures too, especially in the transition economies), the identified miniblocs suggest the likely focus of concerns about bilateral exchange rates of the euro. Casting a wider net, some addi- 
Figure 4

Cluster Based on Vectors of Trade Shares

(Ward's M ethod)

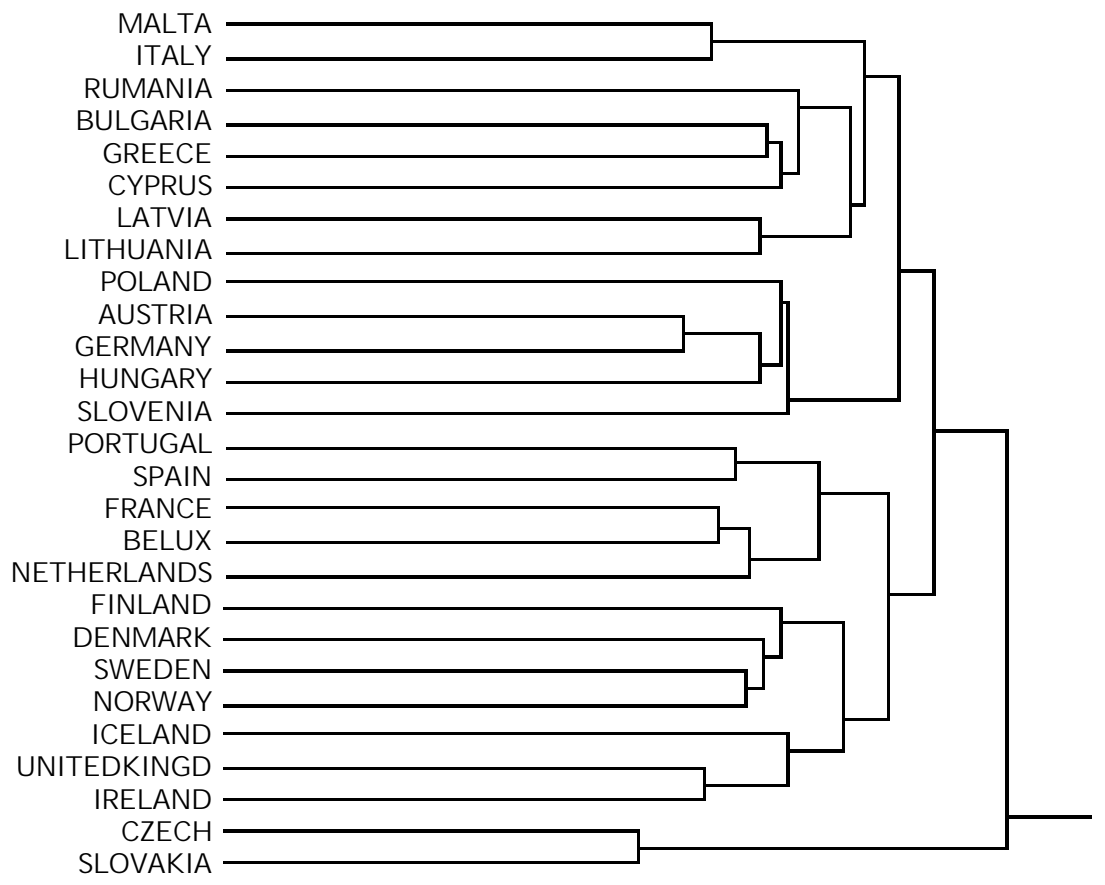

tional dependencies can be foreseen, especially in regard to the tourist trade, with M orocco, Tunisia and Turkey sectorally important competitors for coastal regions of Portugal, Spain and possibly France and Italy.

The three other miniblocs identified by the statistical method are:

Iberian : In addition to important mutual trade, the Iberian minibloc is also marked by having the largest average share of its members' exports (of any minibloc) going to the EU. But this minibloc does not pose any policy issues in the present context, as both the escudo and peseta have been absorbed in the euro.

Hellenistic : Greece forms the core of a minibloc with Cyprus and Bulgaria somewhat analogous to that centered on Italy. There is greater symmetry here in that Greece is an exporting member also. Although Greece was not a starting participant, its early adoption of the euro is likely. 
Baltic : Trade dependency among the three small Baltic states is fairly symmetric, whereas Poland is an importing-only member. It may be noted that several of the countries in the Baltic minibloc are also showing an increasing tendency to trade with $\mathrm{N}$ ordic countries. This minibloc is not be formally split by the euro, but evolving exchange rate policy will move it in that direction.

\section{Policy Practicalities for Collaborative Exchange Rate Arrangements with the Fringe}

If the euro is likely to be a peg or at least the major reference point for many fringe currencies, and if there are significant interests within the EMU area anxious to minimize the amount of competitive depreciation undertaken by minibloc partners, then there is an a priori case for opening the possibility of collaborative ar rangements between the EMU and the fringe. ${ }^{16}$ To have practical importance, such arrangements will have to go beyond the rather wide margins of the ERM -II arrangement. Without entering here into an exhaustive listing of options, the two prime candidates are a currency board arrangement and a looser "target zone" type of regime.

Already Estonia, Bulgaria and Bosnia-Herzegovina have a currency board in effect vis-à-vis the euro, displaying for those cases that the desire to import nominal stability is sufficiently strong not to require any reciprocal arrangement from the side of the EMU. Indeed, it is arguable that the credibility of a currency boards may suffer from being underwritten by the issuer of the peg. The currency boards of Latvia and Lithuania could also switch to a euro peg.

For countries not wishing to adopt a currency board, the alternative of a

16. Of course the alternative to all this is not to see the exchange rate as a target at all. For example, Person and Tabellini [1996] have advocated that (in lieu of the ERM -II) an inflation target should be adopted by non-participant EU countires. This, indeed, is likely to appeal to the UK and many other non-participants in our wider group. From the EM U's point of view, it does have the important advantage of ruling out use of monetary policy for beggar-thy-neighbour policy. H owever, it is less clear that is ensures an optimal adjustment either to non-policy shocks, whether to the real economy or in the demand for money (Wyplosz [1996]). 
search for a viable mechanism for influencing the euro-exchange rate of outsiders thus seems to lead inexorably to something rather flexible. That could very well be along the lines of Williamson's [1985] soft target zone proposal. Recall that this proposal involves setting a target path for the exchange rate, but not undertaking to defend any particular margins around that path. Instead the commitment is a negative one: not to intervene in such a way as to drive the currency away from a zone around the target path. By avoiding intervention commitments, this mechanism opens the door to some degree of collaboration with the ECB that does not present any threat to the latter. It may intervene to help the currency back in the direction of the target zone, or it may choose not to.

The formula is flexible enough to accommodate the type of bargaining implicit in the discussion of Section III above. It could greatly strengthen the ability of an outsider to damp unwanted exchange rate volatility resulting from capital flows, though potentially at the cost of committing to a somewhat less competitive exchange rate strategy.

A typical minibloc target zone would be a bilateral arrangement between the $\mathrm{EMU}$ on the one hand and an outsider on the other. (M ultilateral arrangements, for example involving three Baltic countries and the $E C B$, could also be envisaged.) The elements of the arrangement would include a target zone for the euro exchange rate against the outsider's currency and a special credit facility for the outsider at the ECB. The credit facility would be available to be drawn only when the exchange rate lies outside the target zone.

Each party would undertake, when the exchange rate was outside the target zone, not to take monetary policy actions or exchange market interventions that had the effect of moving the exchange rate further away from the target zone. The ECB would be free to intervene on its own account in the foreign exchange market to buy the outsider's currency if too low or to sell if too high. The outsider would have access to the credit line for the same purpose.

The credit line could be in tranches with a first tranche available either automatically, or by "presumption" (the formula used in the 1987 BaselNyborg agreement on intramarginal intervention in the EMS), together with a further tranche or tranches subject to advance agreement by the 
ECB. A lack of full automaticity would help limit the risk of excessive money base creation in the EMU resulting from inter vention commitments.

Each minibloc target zone arrangement could have its own bilateral steering committee, plausibly including a representative of the affected insider central bank as one of the ECB members of the steering committee. This committee would monitor compliance on a regular basis, and perform the periodic - say, annual - updating of the target zone agreement. Decisions regarding intervention could be made by agreement or unilaterally.

Neither fiscal policy of the EM U countries nor the overall monetary policy of the EM U would be subject to the target zone agreement which (in contrast to that of Williamson) would be an asymmetric one. The policy undertakings would be on the part of the outsider, with the EMU's contribution coming from credit facilities and intervention actions. The fact that fiscal as well as monetary policy actions affect exchange rates suggests that fiscal authorities in the outsider should be explicitly parties to the agreement, despite the principle of central bank independence.

Such an arrangement would survive only if it continued to provide expected benefits to both sides.

For the outsider:

- The gain would be the self-fulfilling nature of an announced target zone against the euro backed by a credit line from the ECB and by the stabilizing force of the joint commitment. Destabilizing speculation would be less likely to succeed than if the outsider had announced an unilateral target zone: the larger credit resources and the different interests of the two parties to the agreement would make defense last longer.

- The cost would be inability to depreciate in a competitive manner. A shock that would normally depreciate the nominal exchange rate would likely be met with offsetting speculative capital movements, as well as intervention by the $E C B$.

For the EMU:

- The gain would be avoidance of competitive depreciation by the outsider.

-- The cost would be the risk of losing money through unsuccessful intervention, and the risk of adding unduly to the EMU's monetary base as a 
result of large-scale intervention in support of the outsider.

Though not all of our miniblocs would generate outsiders wishing to participate in such an arrangement, several may well do. The behavior of fringe currencies matters not only to the fringe, but the $E M U$ itself. It is up to the interested parties within the EMU to make sure that there are institutional facilities for putting such arrangements in place. Since none of the outsiders is sufficiently important for their exchange rate policy to matter for the EMU as a whole, this means that EM U decision-making structures should be open to the minibloc issue and to the potential for mutually acceptable target zone contracts.

\section{References}

Baker, T.J., J. Fitz Gerald and P. Honohan [1996], E conomic Implications for Ireland of EMU, Dublin: ESRI.

Bayoumi, T. and B. Eichengreen [1995], "Is Regionalism Simply a Diversion? Evidence from the Evolution of the EC and EFTA," CEPR Discus sion Paper 1294.

Bayoumi, T. and B. Eichengreen [1996], "Operationalizing the Theory of Optimum Currency Areas," CEPR Discussion Paper 1484.

Ben-David, D. (1995), "Trade and Convergence Among Countries," CEPR Discussion Paper 1126.

Canzoneri, M .B., J. Valles and J. Vinals [1996], "Do Exchange Rates M ove to Address International Macroeconomic Imbalances," CEPR Discus sion Paper 1498.

Curtis, J and J. Fitz Gerald [1994], "Convergence in an Open Labor Market," Working Paper 45, Economic and Social Research Institute.

Demertzis, M., A.J. Hughes Hallett and O.J .Rummel [1996], "Is a Twospeed System in Europe the Answer to the Conflict Between the German and the Anglo-Saxon Models of Monetary Control?" CEPR Dis cussion Paper 1481.

Frankel, J. and A.K. Rose [1996], "The Endogeneity of the Optimum Currency Area Criteria," CEPR Discussion Paper 1473.

Giovanetti G. and R. M arimon [1995], "A M onetary Union for a Heterogeneous Europe", EUI Working Paper RSC N o. 95/ 17, EUI Florence. 
Honohan, P. [1992], "The Link Between Irish and UK Unemployment,"

ESRI Quarterly E conomic Commentary, Spring; pp. 33-44.

Honohan, P. [1997a], "Cur rency B oard or Central Bank?: Lessons from the

Irish Pound's Link with Sterling 1928-79," Banca Nazionale del Lavoro

Quarterly Review 50; pp. 39-67.

Honohan, P. [1997b], "'M iniblocs and Fringe Currencies of the EMU,"

CEPR Discussion Paper 1704.

Honohan, P. and C. Conroy [1994], I rish Interest Rate Fluctuations in the

European M onetary System, Dublin: ESRI.

Hughes Hallett A.J. and Y. M a [1994], "Economic Cooperation Within

Europe: Lessons from the M onetary Arrangements in the 1990s,"

CEPR Discussion Paper 1190.

Kirshner, J. [1995], Currency and Coercion, Princeton, N] : University Press.

Koedijk, K.G. and C.J.M . Kool [1992], "D ominant Interest and Inflation Dif-

ferentials Within the EM S," European Economic Review, Vol. 36, No. 4;

pp. 925-944.

Kremers, J. [1990], "Gaining Policy Credibility for a Disinflation: I reland's

Experience in the EM S," IM F Staff Papers, 37; pp. 116-45.

O bstfeld, M . [1996], "M odels of Currency Crises with Self-fulfilling Fea-

tures," European Economic Review, 40; pp. 1037-48.

Obstfeld, M. and K. Rogoff [1996], F oundations of International M acroeco -

nomics, Cambridge, M ass.: MIT Press.

Persson, T. and G. Tabellini [1996], "Monetary Cohabitation in Europe,"

CEPR Discussion Paper 1380.

Spaventa, L. [1996], "Out in the Cold? O utsiders and Insiders in 1999: Feasi-

ble and Unfeasible Options," CEPR Discussion Paper 1379.

von Hagen, J. and R. Suppel [1994], "Central Bank Constitutions for M one-

tary Unions," CEPR Discussion Paper 919.

von Hagen, J. and G.W. Hammond [1995], "Regional Insurance Against

Asymmetric Shocks: An E mpirical Study for the European Communi-

ty," CEPR Discussion Paper 1170.

Williamson, J. [1985], The Exchange Rate System (2nd eds), Washington,

D.C.: Institute for International Economics.

Wyplosz, C. [1996], "M onetary Options for the 'Outs'," Conference Paper. 


\section{Appendix}

\section{A Model of the Potential for Mutually Beneficial Exchange Rate Arrangements with Minibloc Outsiders}

A very simple model will illustrate the kind of linkage between particular participants and certain outsiders that could be the subject of a side arrangement. Two important simplifications need to be highlighted. First, we ignore interest rates, bearing in mind that the EMU-wide interest rate can be taken as given for any particular participant $P$. Second, we work in real terms, neglecting any formal treatment of inflation. This latter simplification reflects the stylized fact that nominal exchange rate movements dominate real movements at high frequencies. Thus we concentrate on the role of the real exchange rate $z$ in the aggregate supply and demand curves for countries $\mathrm{i}=\mathrm{P}, \mathrm{N}$ :

$$
\begin{aligned}
& y_{i}^{D}=u_{i}+v-z_{i} \\
& y_{i}^{S}=z_{i}
\end{aligned}
$$

Here $u_{i}$ and $v$ are (mutually uncorrelated) country-specific and common shocks respectively, where by a common shock is meant a shock that hits both $\mathrm{P}$ and the particular outsider in question $\mathrm{N}$, but does not hit the rest of the EMU. Since P's exchange rate with the euro is fixed, and since N's exchange rate with the rest of the world is proportionate to its exchange rate with the euro $s_{N}$, we may write the effective exchange rate for the two countries as:

$$
\begin{aligned}
& z_{N}=s_{N} \\
& z_{p}=-s_{N}=-z_{N}
\end{aligned}
$$

where $\tau$ is the weight of country $N$ in the effective exchange rate index for $P$.

\section{Case 1: Outsider's Exchange Rate Clears the Goods Market.}

If there are no capital flows and no official exchange market interventions, then the outsider's exchange rate will adjust in equilibrium to clear the goods market. Thus, in this case we can solve for $z_{N}$ : 


$$
z_{N}=\frac{1}{+}\left(u_{N}+v\right)
$$

N's output thus fluctuates along the supply curve, with

$$
\begin{aligned}
& y_{n}=(1-)\left(u_{n}+v\right) \\
& \operatorname{Var}\left(y_{n}\right)=(1-)^{2}\left(\begin{array}{c}
2 \\
u
\end{array}+\underset{v}{2}\right)
\end{aligned}
$$

where,

$$
=\frac{}{+}
$$

This exchange rate response to demand disturbances in $\mathrm{N}$ passes through to the demand for P's output. Assuming that the P's output is demand-determined in the short-run, we obtain:

$$
\begin{aligned}
& y_{p}=u_{p}+u_{N}+(1+\quad) v \\
& \operatorname{Var}\left(y_{p}\right)=\left(1+2{ }^{2}\right){ }_{u}^{2}+(1+\quad)^{2}{ }_{v}^{2}
\end{aligned}
$$

Now if we treat the variance of the gap between supply and demand as a loss function, its value for the outsider $N$ is zero, but for the participant $P$ it is:

$$
L_{p}=\left(1+{ }^{2}\right) \underset{u}{2}+(+)^{2}{ }_{v}^{2}
$$

This, then is the cost of asymmetric shocks. The terms in $\tau$ are the additional loss due to the fact that the outsider's exchange rate adjusts to the shock. P would prefer N's exchange rate not to adjust. Indeed, P's preference would be for the opposite movement by N. B ut in this simple model $P$ has nothing to offer $\mathrm{N}$, as $\mathrm{N}$ 's loss function is al ready at its minimum value of zero.

\section{Case 2: Misalignments due to Capital Flows}

Adding a destabilizing capital flow in the determination of $\mathrm{N}$ 's exchange rate brings in the possibility of mutual gain. The essential idea is that the outsider may be adversely affected by capital flows, and may gain from an exchange rate arrangement which insulates from these, even if it leads to an exchange rate evolution different to what would be optimal in the absence 
of capital flow shocks.

We model these capital flows as adding a further stochastic term $w$ to the expression for exchange rate $z_{N}$. The loss functions then become:

$$
\begin{aligned}
& L_{N}=(+)^{2}{ }_{w}^{2} \\
& L_{p}=\left(1+{ }^{2}\right) \underset{u}{2}+(1+)^{2}{ }_{v}^{2}+{ }^{2}(+)^{2} \underset{w}{2}+\text { Covariances }
\end{aligned}
$$

So far, there is no policy instrument specified. Implicitly we are assuming that $\mathrm{N}$ is unable to influence its exchange rate. This is indeed an extreme way of characterizing the situation even of a small country with an open capital market, but serves to introduce the possibility of mutual gain if the $E M U$, being large and credible, can join with $\mathrm{N}$ to achieve a particular exchange rate path offering some reduction in $L_{N}$. For example, if it were possible for the EM U and $\mathrm{N}$ jointly to enforce a linear exchange rate rule:

$$
z_{N}=\frac{1}{+}\left(a u_{N}+b v\right)
$$

thereby in particular eliminating the capital flow shocks, then it would be possible to reduce both loss functions. For example, the zero loss for $\mathrm{N}$ could be achieved by setting $a=b=1$. But bargaining over $a$ and $b$ would allow $P$ to achieve a greater loss reduction than implied by this at some cost to N. Figure A.1 displays the indifference curves for $N$ and $P$ in this case. The curves are based on:

$$
\begin{aligned}
& L_{N}=(1-a)^{2} \underset{u}{2}+(1-b)^{2}{ }_{v}^{2} \\
& L_{p}=\left(1+{ }^{2} a^{2}\right){ }_{u}^{2}+(1+b)^{2}{ }_{v}^{2}
\end{aligned}
$$

The best choice for $P$ is $a=0, b=-1 / \tau$. Note that, as this policy also suppresses the speculative variance ${ }_{w}^{2}$, the utility of the free-float solution cannot be read off Figure A.1

The cooperative solution within the class of linear exchange rate rules is somewhere along the contract curve of points of tangency. In general, an interior solution will involve only partially moving $N$ 's exchange rate to offset the idiosyncratic demand shock $u_{N}$, and possibly even acting to exacerbate (from N's point of view) the impact of the common shock $v$, by choosing $b<0$. This indicates the scope for bargaining, and also hints at the desir- 
Figure A. 1

Indiference Curves

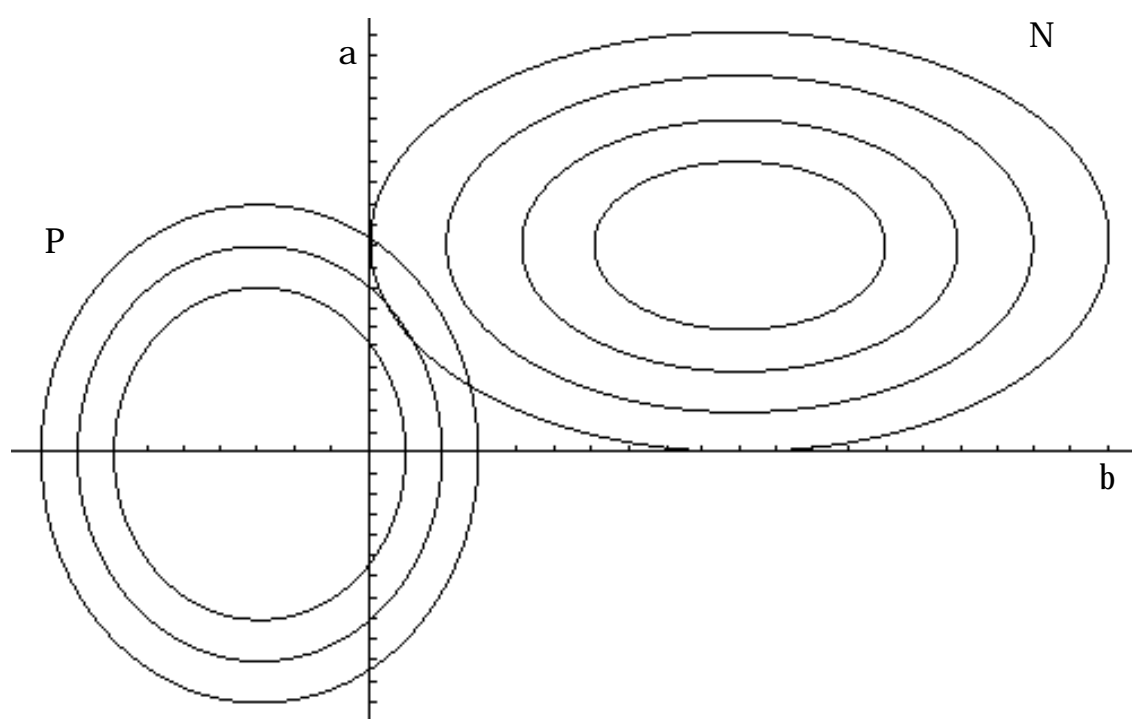

ability of some form of policy rule agreed in advance. ${ }^{17}$

\section{Hedging}

Regional insurance as an alternative to exchange rate policy is usually discussed in terms of a centralized fiscal mechanism (cf. von Hagen and Hammond [1995]. But the present set-up points in the direction of an alternative form of insurance through the market. Instead of trying to act on N's exchange rate, $P$ could adopt the alternative of using a financial instrument correlated with $z_{N}$ to offset or hedge the income effects. For instance, if an instrument paying $c z_{N}$ were purchased, then the variance of P's income $y_{p}+$ $C Z_{N}$ could be minimized by choosing

$$
c=-\quad-(+) \frac{2}{\frac{v}{2}+{ }_{v}^{2}}
$$

17. In the terminology of Hughes Hallett and $\mathrm{M} \mathrm{a}$ [ 1995], this is a form of domain solution. As such it leaves open a number of issues of incentive compatibility to which we return below. 
In practice, such a financial hedge is not unusual. For example, it can be effected through choice of currency denomination of official foreign currency debt. But if $\mathrm{N}$ is a small country, such financial transactions may not be attainable without influencing the spot exchange rate. This suggests that the option of hedging may be relatively more effective for large countries $\mathrm{N}$ while the exchange rate cooperation may be more attainable for small countries N. 